\title{
Aplikasi Penghitungan Gross Primary Production dari Data Penginderaan Jauh
}

\author{
Komang Gede Kurniadi ${ }^{1}$, I Putu Agung Bayupati², I Dewa Nyoman Nurweda Putra ${ }^{3}$ \\ Jurusan Teknologi Informasi, Fakultas Teknik, Universitas Udayana \\ Bukit Jimbaran, Bali, Indonesia \\ ${ }^{1}$ komanggedekurniadi@gmail.com \\ 2bayuhelix@yahoo.com \\ 3nurweda14@gmail.com
}

\begin{abstract}
Abstrak
Penghitungan Gross Primary Production yang memanfaatkan data penginderaan jauh dapat dilakukan dengan aplikasi penginderaan jauh komersil. Penghitungan Gross Primary Production pada aplikasi penginderaan jauh komersil dilakukan secara manual. Penghitungan dengan cara manual ini dikarenakan aplikasi tersebut tidak menyediakan fungsi khusus untuk memungkinkan pengguna dapat menghitung Gross Primary Production. Penelitian ini bertujuan untuk merancang sebuah aplikasi penginderaan jauh yang khusus digunakan untuk melakukan penghitungan Gross Primary Production untuk daerah Denpasar. Aplikasi yang dibuat adalah aplikasi yang dapat menerima input berupa data penginderaan jauh yaitu citra satelit Landsat 8 OLI and TIRS dan file metadata. Rumus-rumus dan data pendukung yang diperlukan untuk menghitung Gross Primary Production diimplementasi pada aplikasi untuk dapat mengolah citra secara otomatis. Fitur-fitur tambahan seperti parsing data dari file metadata, cropping, masking dan zoom juga disediakan pada aplikasi untuk mempermudah pengguna dalam melakukan penghitungan Gross Primary Production. Aplikasi dapat menghasilkan informasi berupa nilai Gross Primary Production yang dituangkan dalam bentuk gambar dengan segmentasi warna, luas dari masing-masing segmen dan nilai Gross Primary Production rata-rata, minimum dan maksimum.
\end{abstract}

Kata kunci: aplikasi, penginderaan jauh, Gross Primary Production, Landsat 8, Denpasar.

\begin{abstract}
Calculation of Gross Primary Production that utilize remote sensing data is can be done on commercial remote sensing software by manual method. The commercial remote sensing software does not provides a specific feature that allow the user to do the Gross Primary Production calculation. This research is aimed to to build a remote sensing software that can be specifically used to do the Gross Primary Production calculation for Denpasar area. This software accepts remote sensing data as an input, such as satellite image from Landsat 8 OLI and TIRS and metadata file. The formulas and supporting data that required on the Gross Primary Production calculation are implemented on software in order to make an automatic image processing software. There also some additional feature on this software such as automatic data parsing from metadata file, cropping, masking and zoom that could help user to do the Gross Primary Production calculation. The developed software is able to produce information such as Gross Primary Production value that depicted by a figure with color segmentation, area of the segments and mean, minimum and maximum value of the Gross Primary Production.
\end{abstract}

Keywords: software, remote sensing, Gross Primary Production, Landsat 8, Denpasar. 


\section{Pendahuluan}

Perubahan iklim dan pemanasan global merupakan masalah yang sangat serius di mata dunia. Salah satu penyebab masalah-masalah tersebut adalah meningkatnya emisi karbon pada atmosfir [1]. Peningkatan emisi karbon ini salah satunya disebabkan oleh kurangnya vegetasi yang berperan untuk mengimbangi emisi karbon hasil dari aktifitas manusia seperti asap kendaraan, asap pabrik dan berbagai bentuk emisi karbon yang lainnya. Penghitungan karbon pada atmosfir sangat diperlukan untuk dapat digunakan dalam pengambilan langkah yang tepat untuk mengatasi masalah tersebut.

Gross Primary Production merupakan salah satu metode untuk memperkirakan penyerapan karbon oleh vegetasi. Metode ini memanfaatkan data penginderaan jauh yaitu citra satelit. Citra satelit digunakan untuk mengetahui tutupan vegetasi dengan cara menghitung indeks vegetasi. Penghitungan Gross Primary Production dengan bantuan citra satelit dapat dilakukan dengan software penginderaan jauh komersil. Software penginderaan jauh komersil tidak menyediakan fungsi khusus untuk memungkinkan pengguna dapat melakukan penghitungan Gross Primary Production. Pengguna harus menyusun rumus penghitungan Gross Primary Production secara manual ke dalam software penginderaan jauh tersebut.

Aplikasi yang dibuat dalam penelitian ini adalah aplikasi penginderaan jauh yang dirancang khusus untuk menghitung Gross Primary Production di daerah Denpasar. Rumus-rumus yang diperlukan seperti koreksi reflektan citra satelit, penghitungan NDVI, thresholding NDVI, penghitungan fraction Absorbed Photosynthetically Active Radiation (fAPAR), Photosynthetically Active Radiation (PAR) dan Gross Primary Production perlu dituangkan ke dalam aplikasi khusus agar dapat melakukan penghitungan secara otomatis, dengan data Incoming Solar Radiation (ISR) sebagai data pendukung. Aplikasi yang dirancang juga dilengkapi dengan fitur cropping dan masking untuk dapat mengolah citra satelit yang belum diolah sama sekali.

\section{Metodologi Penelitian}

Berikut ini merupakan gambaran umum dari aplikasi yang dikembangkan. Gambaran umum sistem menjelaskan mengenai alur aplikasi dari input sampai output.

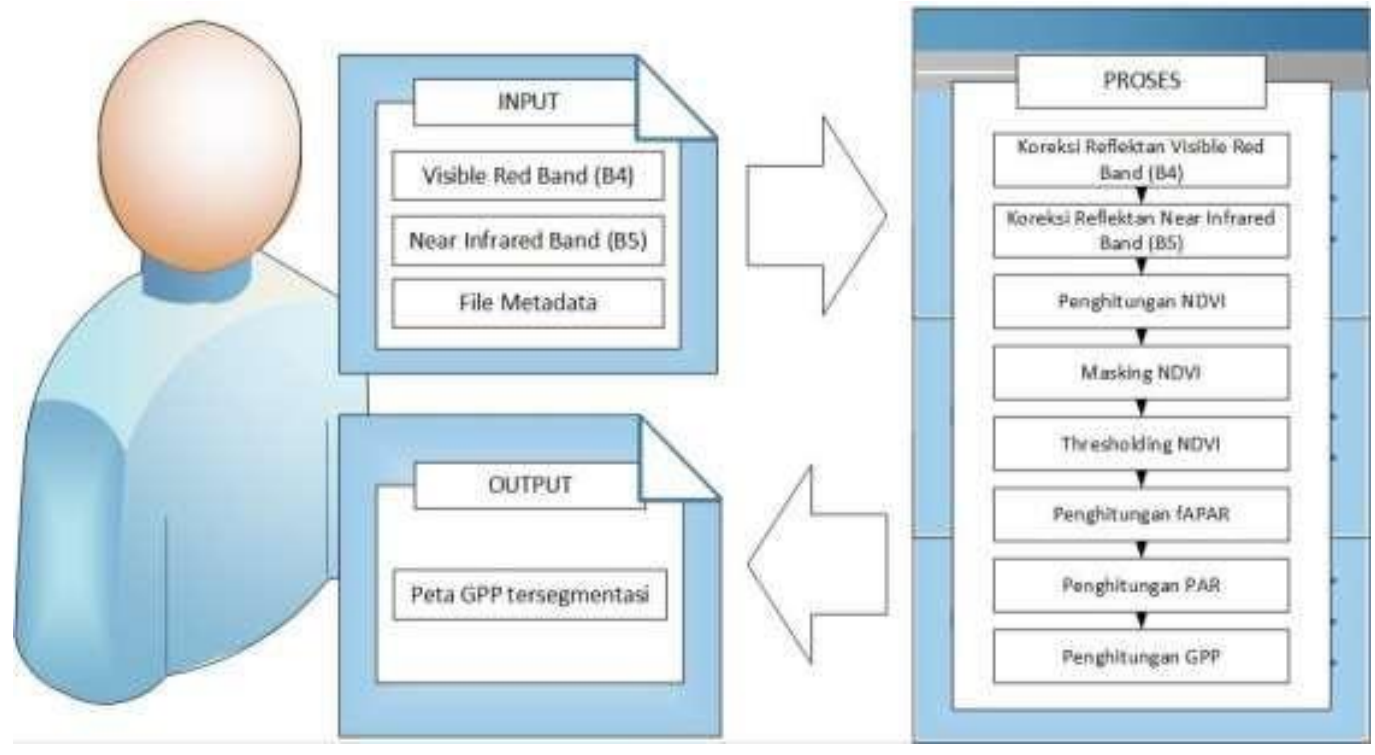

Gambar 1. Gambaran Umum Sistem

Gambar 1 merupakan gambaran umum aplikasi penghitungan Gross Primary Production yang dibuat. Aplikasi yang dibuat memiliki 2 jenis input yaitu input citra dan input angka variabel. Input citra yang dimaksud adalah citra satelit yang berformat GeoTIFF, sedangkan input angka variabel adalah variabel Incoming Solar Radiation (ISR) dan Light Use Efficiency (LUE). Proses 
yang terdapat pada aplikasi adalah proses koreksi reflektan dari masing-masing citra yang diinput-kan, proses penghitungan tutupan vegetasi dengan NDVI, proses masking citra NDVI, proses penghitungan fAPAR, proses penghitungan PAR, dan proses penghitungan Gross Primary Production. Sedangkan output yang dihasilkan aplikasi adalah peta Gross Primary Production yang sudah tersegmentasi.

\section{Kajian Pustaka}

\subsection{Penginderaan Jauh}

Penginderaan jauh adalah cabang ilmu untuk memperoleh informasi tentang permukaan bumi tanpa bersentuhan langsung dengan objek tersebut [2]. Karakteristik yang diukur oleh sensor adalah energi elektromagnetik yang dipantulkan atau dipancarkan oleh permukaan bumi.

Penginderaan jauh didasari oleh perbedaan dari permukaan bumi berdasarkan pantulan spektralnya. Reflektansi spektral (seperti warna dan corak), analis akan menggunakan kriteria lain pada proses kognitif visual dalam menginterpretasi citra penginderaan jauh, seperti tekstur, pola, ukuran, bentuk, bayangan, dan konteks. Metode yang paling banyak digunakan dalam klasifikasi yang dibantu oleh komputer dalam pengolahan data penginderaan jauh yang tidak melibatkan manusia sebagai pengamat adalah dengan memanfaatkan pendekatan "per piksel, data spektral tunggal" [3].

\subsection{Indeks Vegetasi}

Penghitungan indeks vegetasi biasanya menggunakan perhitungan aljabar sederhana, indeks vegetasi didesain untuk memperkuat sinyal vegetasi pada data yang didapat dengan penginderaan jauh dan menyediakan ukuran perkiraan dari jumlah vegetasi yang hijau dan sehat[4]. Normalized Difference Vegetation Index (NDVI) merupakan alat yang popular untuk menilai berbagai aspek dari proses tanaman, ketika secara simultan menentukan variasi spasial pada tutupan vegetasi [4].

$$
N D V I=\frac{\text { Near Infrared Band }- \text { Visible Red Band }}{\text { Near Infrared Band }+ \text { Visible Red Band }}
$$

Pengukuran vegetasi menggunakan NDVI membutuhkan dua input yaitu band Near Infrared dan band Visible Red. Penggunaan dua input tersebut didasari oleh teori bahwa tumbuhan sehat cenderung memberi banyak pantulan pada gelombang Near Infrared dan sedikit pantulan (lebih banyak menyerap) gelombang tampak atau visible [5].

NDVI tersebar antara 0 dan 1 untuk permukaan bervegetasi, gurun memiliki nilai mendekati nol dan hutan tropis mendekati 1 [6]. Berikut ini merupakan tabel yang menunjukkan hubungan antara rentang nilai NDVI dengan objek pada permukaan bumi [7].

Tabel 1. Korelasi antara nilai NDVI terhadap objek pada permukaan bumi

\begin{tabular}{cc}
\hline $\mathrm{NDVI}$ & Objek \\
\hline$<0,1$ & Bebatuan, tanah tandus, pasir, salju \\
$0,2-0,5$ & $\begin{array}{c}\text { Vegetasi jarang: Semak-semak, padang rumput, } \\
\text { tamanan menua }\end{array}$ \\
$0,6-0,9$ & $\begin{array}{c}\text { Vegetasi padat: hutan beriklim sedang, hutan tropis, } \\
\text { tumbuh-tumbuhan sehat }\end{array}$ \\
\hline
\end{tabular}

Nilai NDVI yang kurang dari 0,1 pada Tabel 1 merupakan objek-objek non-vegetasi seperti bebatuan, tanah tandus, pasir dan salju. Nilai NDVI pada rentang 0,2-0,5 mewakili tutupan vegetasi yang tidak begitu tebal seperti semak-semak, padang rumput dan tamanan menua. Nilai NDVI pada rentang 0,6-0,9 merupakan tutupan vegetasi rapat seperti hutan beriklim sedang, hutan tropis dan tumbuh-tumbuhan sehat.

\subsection{Satelit Landsat 8}

Satelit Landsat yang terbaru adalah Landsat $8 \mathrm{OLI}$ and TIRS yang diluncurkan pada 11 
Februari 2013 dari Vandenberg Air Force Base, California pada roket Atlas-V 401 dengan Extended Payload Fairing (EPF) dari United Launch Alliance, LLC. Landsat 8 OLI AND TIRS dilengkapi oleh 2 sensor yaitu Operational Land Imager (OLI) dan Thermal Infrared Sensor (TIRS) yang menyediakan cakupan musiman dari daratan global pada resolusi spasial 30 meter (Visible, NIR, SWIR), 100 meter (Thermal) dan 15 meter (Panchromatic) [8].

Nilai piksel pada citra satelit komersil menunjukkan paparan dari permukaan bumi dalam bentuk Digital Number (DN) yang dikalibrasi ke suatu rentang nilai. Konversi DN ke dalam paparan nyata perlu dilakukan untuk analisis komparatif dari beberapa citra yang diambil oleh sensor yang berbeda. Persamaan koreksi reflektan untuk citra satelit Landsat 8 . Persamaannya adalah sebagai berikut [9].

$$
\rho \lambda=\frac{M_{\rho} Q_{c a l}+A_{\rho}}{\sin \left(\theta_{S E}\right)}
$$

Keterangan:

$\rho \lambda=$ TOA planetary reflectance

$M_{\rho} \quad=$ Band-specific multiplicative rescaling factor dari metadata

(REFLECTANCE_MULT_BAND_x, di mana x adalah nomor band)

$A_{\rho}=$ Band-specific additive rescaling factor dari metadata

(REFLECTANCE_ADD_BAND_x, di mana $\mathrm{x}$ adalah nomor band)

$Q_{c a l}=$ Quantized and calibrated standard product pixel values (DN)

$\theta_{\mathrm{SE}} \quad=$ Local sun elevation angle (SUN_ELEVATION)

Nilai $M_{\rho}$ dan $A_{\rho}$ berbeda di tiap-tiap band dari citra yang diakuisisi oleh masing-masing sensor. Indeks vegetasi dicari menggunakan NDVI dengan input band Visible Red dan band Near Infrared, sehingga koreksi reflektan dilakukan pada masing-masing citra band tersebut.

\subsection{Gross Primary Production}

Gross Primary Production atau produksi primer kotor didefinisikan sebagai fluks karbon dioksida $\left(\mathrm{CO}_{2}\right)$ yang diserap ke dalam tanaman melalui fotosintesis yang merupakan kuantitas fisik dasar untuk penghitungan keseimbangan karbon antara atmosfer dengan biosfer terestrial [10]. Tumbuhan menggunakan energi matahari dalam reaksi kimia yang mengubah air dan karbon dioksida menjadi karbohidrat [4]. Telah dikembangkan sebuah metode untuk memperkirakan produktivitas tanaman dari observasi absorbed photosynthetically active radiation (APAR) dan perkiraan Light-Use Efficiency (LUE) [11]. Persamaannya adalah sebagai berikut:

$$
G P P=L U E \times f A P A R \times P A R
$$

GPP adalah Gross Primary Productivity $\left(\mathrm{gC} \mathrm{m}^{-2}\right.$ waktu $\left.^{-1}\right)$, fAPAR adalah Fraction Absorbed Photosynthetically Active Radiation (MJ $\mathrm{m}^{-2}$ waktu $^{-1}$ ), PAR adalah Photosynthetically Active Radiation (MJ m-2 waktu $^{-1}$ ) dan LUE adalah Light-Use Efficiency (gC MJ $\left.{ }^{-1}\right)$. Rekomendasi nilai Light-Use Efficiency yaitu $1.5 \mathrm{gC} \mathrm{MJ}^{-1}$ untuk beberapa negara Asia [12].

\subsubsection{Fraction Absorbed Photosynthetically Active Radiation (fAPAR)}

Hubungan antara NDVI dan fAPAR dapat digunakan untuk menentukan total penyerapan $\mathrm{CO}_{2}$ oleh vegetasi atau Gross Primary Production menggunakan model dari Light Use Efficiency (LUE) [13]. Berikut adalah rumus hubungan fAPAR dan NDVI di beberapa negara Asia yang direkomendasikan [12].

$$
f A P A R=-0,08+1,075 N D V I
$$

NDVI merupakan data input berupa citra pada rumus di atas, sehingga operasi perkalian angka terhadap NDVI dilakukan pada seluruh piksel pada citra tersebut. Operasi penjumlahan juga dilakukan terhadap seluruh piksel hasil dari perkalian NDVI dengan pengalinya. 


\subsubsection{Photosynthetically Active Radiation (PAR)}

Photosynthetically Active Radiation atau disingkat PAR merupakan salah satu bagian dari spektrum radiasi matahari yang termasuk dalam cahaya tampak [14]. Proses asimilasi atau fotosintesis tumbuhan membutuhkan cahaya matahari [15] dan tanaman hanya menginterpretasi setengah dari radiasi cahaya matahari [16]. Formula untuk menghitung PAR berdasarkan dasar teori di atas adalah sebagai berikut:

$$
P A R=0,5 \times I S R
$$

Tabel 2. Data nilai ISR perbulan di Kota Denpasar [17]

\begin{tabular}{ccc}
\hline Bulan & Nilai $\left(\mathrm{MJ} / \mathrm{m}^{2} /\right.$ hari) & Nilai $\left(\mathrm{MJ} / \mathrm{m}^{2} /\right.$ bulan $)$ \\
\hline Januari & 16.3 & 505.3 \\
Februari & 18.4 & 515.2 \\
Maret & 17.8 & 551.8 \\
April & 18.2 & 546.0 \\
Mei & 16.2 & 502.2 \\
Juni & 15.0 & 450.0 \\
Juli & 15.0 & 465.0 \\
Agustus & 18.6 & 576.6 \\
September & 19.7 & 591.0 \\
Oktober & 20.1 & 623.1 \\
November & 19.5 & 585.0 \\
Desember & 17.3 & 536.3 \\
\hline Total (Nilai $\left(\mathrm{MJ} / \mathrm{m}^{2} /\right.$ tahun) \\
\hline \multicolumn{2}{c}{}
\end{tabular}

Data pada Tabel 2 di atas merupakan data ISR perbulan yang merupakan hasil dari penghitungan rata-rata ISR perbulan pada tahun 1969-1973 [17]. Data diperoleh dari hasil penghitungan rata-rata karena pada interval tahun 1969-1973 terdapat data yang tidak didapat pada bulan-bulan tertentu.

\section{Hasil dan Pembahasan}

Aplikasi yang dirancang adalah aplikasi pengolah citra berbasis desktop. Graphical User Interface dari aplikasi disusun secara sederhana agar menjadi user friendly. Berikut ini merupakan tampilan dari Jendela Utama aplikasi yang dirancang.

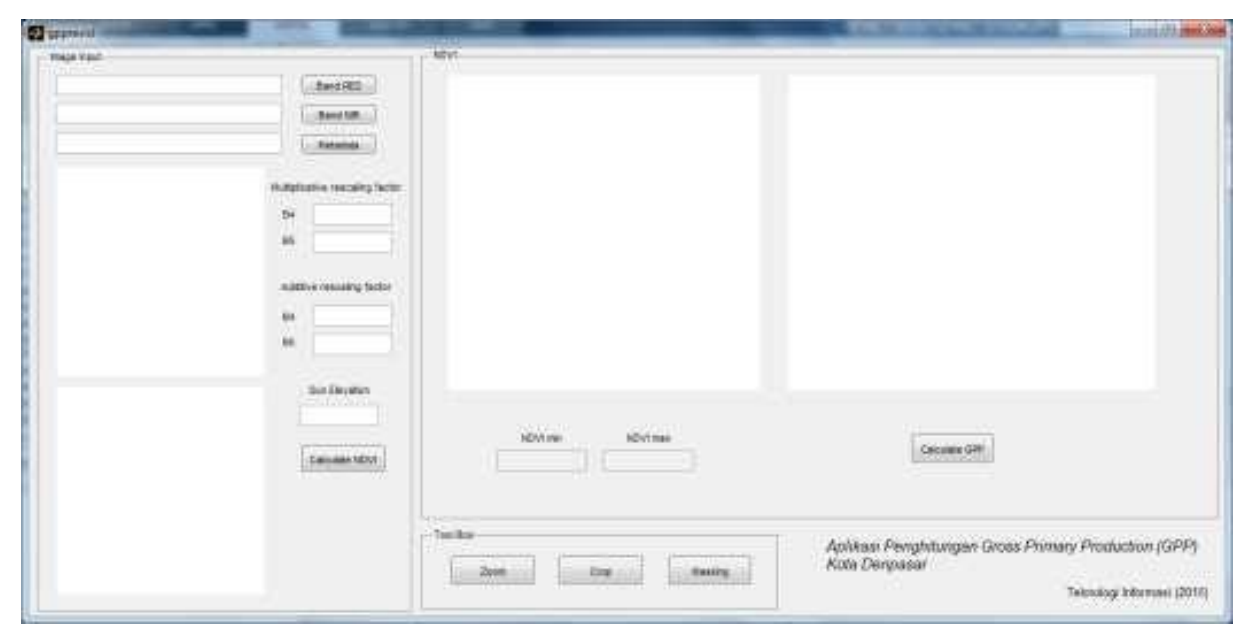

Gambar 2. Jendela Utama 
Panel Image Input pada Gambar 2 mengandung tiga tombol untuk melakukan input citra satelit \& file metadata dan satu tombol untuk menjalankan perhitungan NDVI. Bagian atas pada panel kiri terdapat tiga textbox panjang untuk menampilkan fullpath dari Visible Red Band, Near Infrared Band dan file metadata. Bagian ini juga memiliki dua panel gambar untuk menampilkan Visible Red Band dan Near Infrared Band. Lima textbox pendek berfungsi untuk menampilkan nilai ketinggian matahari, multiplicative rescaling factor untuk Visible Red Band dan Near Infrared Band, dan additive rescaling factor untuk Visible Red Band dan Near Infrared Band yang di-parsing dari file metadata. Panel NDVI digunakan untuk menampilkan hasil penghitungan NDVI. Dua panel gambar bertujuan untuk menampilkan hasil penghitungan NDVI dan menampilkan hasil threshold NDVI. Proses masking NDVI dapat dilakukan pada panel gambar NDVI. Dua textbox pada panel ini berfungsi untuk menampilkan nilai NDVI minimum dan maksimum. Tombol "Calculate GPP" berfungsi untuk menjalankan fungsi penghitungan Gross Primary Production. Panel Tool Box pada Gambar 2 mengandung tiga tombol yaitu tombol Zoom, Crop dan Masking. Masing-masing tolbol tersebut memiliki fungsi yang berbedabeda. Tombol Zoom berfungsi untuk menampilkan gambar lebih dekat atau detil dari panel gambar yang di-zoom. Tombol Crop menjalankan fungsi memotong citra satelit input untuk mendapatkan daerah yang diteliti. Tombol Masking berfungsi untuk menjalankan fungsi masking untuk memotong daerah yang diteliti dengan menggunakan poligon yang dapat dibuat secara manual oleh user. Hasil penghitungan Gross Primary Production ditampilkan pada jendela terpisah. Berikut merupakan tampilan dari Jendela GPP.

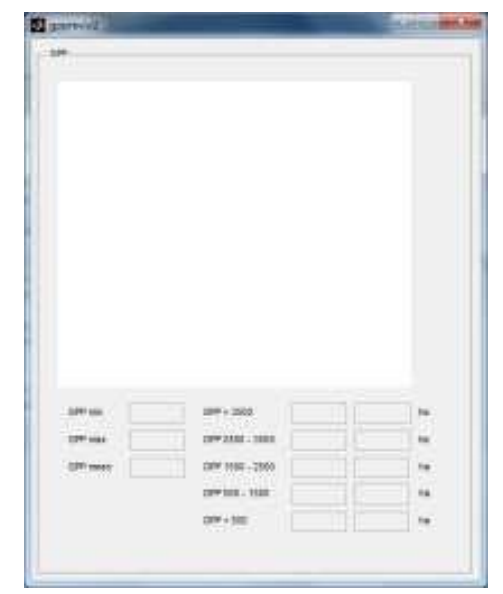

Gambar 3. Jendela GPP

Jendela GPP pada Gambar 3 mengandung sebuah panel gambar untuk menampilkan hasil penghitugan Gross Primary Production. Tiga textbox pada bagian kiri bawah untuk menampilkan nilai minimum, maksmum dan rata-rata Gross Primary Production. Lima pasang textbox pada bagian kanan bawah untuk menampilkan jumlah piksel dan luas dari lima rentang nilai Gross Primary Production. 

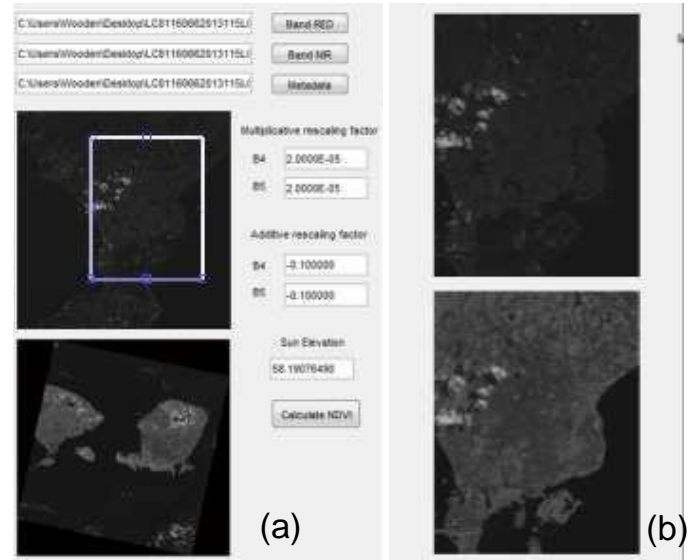

Gambar 4. Proses pada Panel Input

Terdapat beberapa proses yang terjadi pada Panel Input diantaranya, proses input citra satelit, proses input file metadata, proses menampilkan citra satelit input, proses menampilkan filepath citra input dan file metadata, proses menampilkan nilai-nilai variabel untuk koreksi reflektan dan proses cropping citra input. Gambar 4(a) merupakan tampilan dari filepath seluruh file input, tampilan citra satelit input yaitu Visible Red Band (atas) dan Near Infrared Band (bawah), tampilan nilai-nilai variabel untuk koreksi reflektan. Proses cropping juga dapat dilakukan pada panel gambar Visible Red Band. Proses ini hanya dibutuhkan sekali untuk kedua citra satelit input. Gambar 4(b) merupakan tampilan dari citra satelit Visible Red Band (atas) dan Near Infrared Band (bawah) setelah melewati proses cropping. Proses penghitungan indeks vegetasi dapat dilakukan dengan meng-klik tombol "Calculate NDVl".

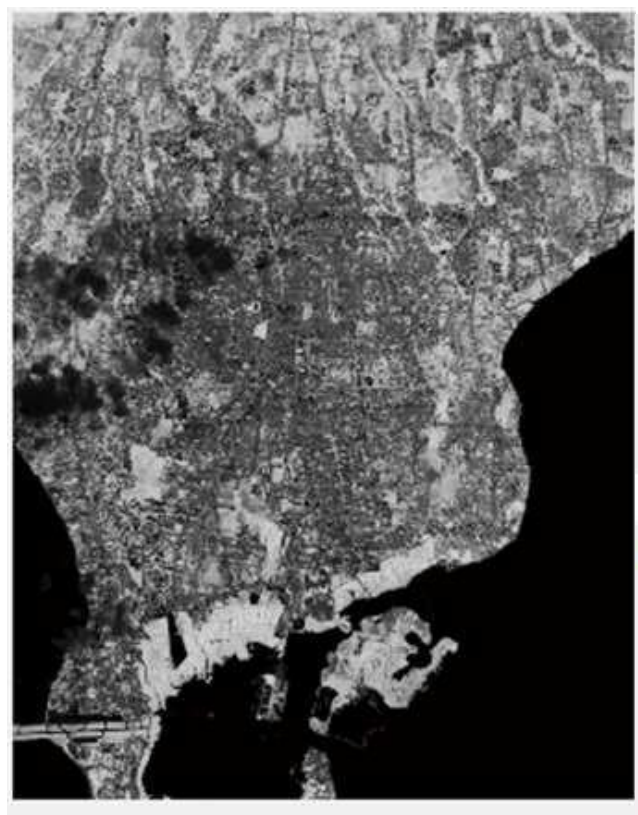

(a)

NDVI min

$-0.867403$
NDVI max

0,838116

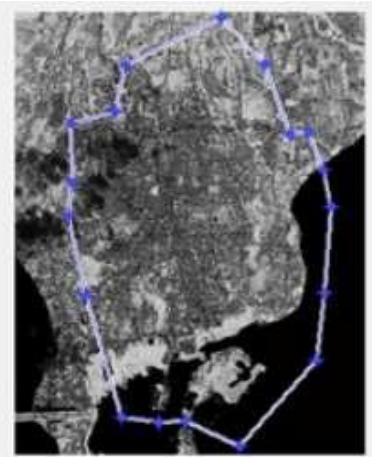

(b)

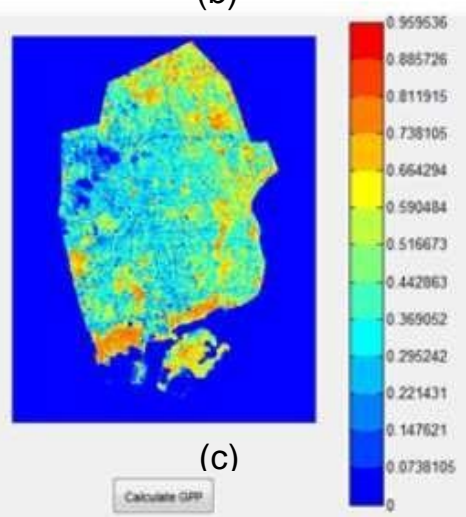

Gambar 5. Proses pada Panel NDVI 
Proses penghitungan indeks vegetasi menghasilkan keluaran berupa citra NDVI. Gambar 5(a) merupakan citra NDVI yang ditampilkan pada panel gambar dengan corak warna keabuan. Masing-masing gradasi mewakili interpretasi yang berbeda-beda terhadap tutupan vegetasi. Semakin putih sebuah piksel maka piksel tersebut semakin dekat dengan nilai 1, sedangkan semakin gelap menunjukkan bahwa nilai intensitas tutupan vegetasi pada piksel tersebut semakin dekat dengan -1. Area hitam pada bagian kanan dan kiri gambar merupakan lautan, tetapi titik-titik hitam yang tersebar di tengah-tengah gambar merupakan awan yang berada di atas daratan. Nilai indeks vegetasi minimum dan maksimum juga ditampilkan pada aplikasi. Gambar 5(b) merupakan proses masking yang dilakukan pada citra NDVI. Proses ini bertujuan untuk memotong daerah yang hendak diteliti yaitu Kota Denpasar. Poligon yang digambar di atas panel citra NDVI menandakan bahwa daerah tersebut merupakan daerah yang diteliti. Gambar 5(c) merupakan hasil dari proses masking yaitu citra NDVI yang telah dipotong berdasarkan poligon yang dibuat secara manual oleh user. Citra NDVI yang sudah di- masking diberi corak warna berdasarkan nilai indeks vegetasi dalam rentang tertentu. Terdapat sebuah colorbar di sebelah kanan yang berfungsi sebagai indikator warna dari masing-masing rentang nilai dari indeks vegetasi.

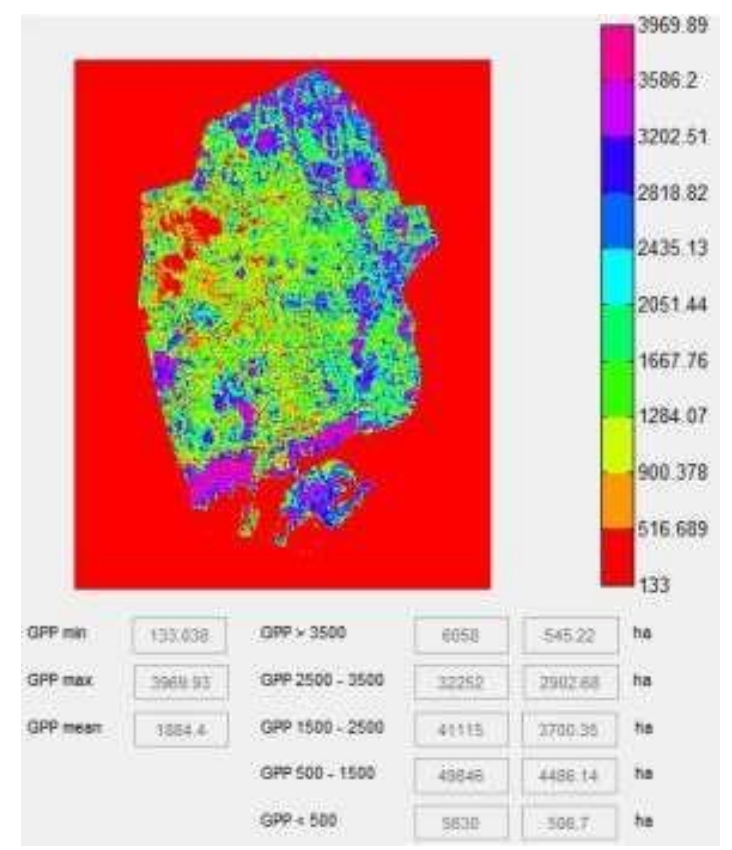

Gambar 6. Proses pada Panel GPP

Gambar 6 merupakan tampilan hasil penghitungan Gross Primary Production pada aplikasi. Citra Gross Primary Production disegmentasi ke dalam beberapa warna yaitu, merah muda, ungu, biru tua, biru sedang, biru muda, hijau, hijau muda, kuning, jingga dan merah. Nilai Gross Primary Production terendah digambarkan dengan warna merah sedangkan nilai tertinggi digambarkan dengan warna merah muda. Nilai Gross Primary Production rendah berarti penyerapan karbon pada daerah tersebut rendah. Daerah berwarna merah diluar daerah lautan dan awan di peta Gross Primary Production memiliki potensi rendah dalam penyerapan karbon. Daerah ini memiliki nilai yang berbanding lurus dengan nilai NDVI yang rendah, karena nilai NDVI yang rendah baerarti memiliki tutupan vegetasi rendah. Daerah merah ini merupakan daerah non-vegetasi seperti lahan kosong, bangunan perkotaan, air, dan objek-objek nonvegetasi lainnya. Daerah yang berwarna jingga dan kuning juga memiliki potensi rendah dalam penyerapan karbon, tetapi tidak serendah area merah. Daerah berwarna merah muda menunjukkan nilai Gross Primary Production yang tinggi, sehingga menunjukkan potensi penyerapan karbon pada daerah tersebut tinggi. Daerah merah muda ini juga memiliki nilai yang berbanding lurus dengan tingginya nilai indeks vegetasi. Berarti daerah ini memiliki tutupan vegetasi yang tinggi. Area merah muda yang luas pada citra Gross Primary Production adalah daerah yang memiliki potensi penyerapan karbon tinggi. Daerah tersebut merupakan 
hutan mangrove di wilayah selatan dari Kota Denpasar. Daerah ungu dan biru juga merupakan potensi karbon penyerapan yang tinggi, tetapi lebih rendah dari daerah berwarna merah muda. Nilai maksimum, minimum dan rata-rata Gross Primary Production juga ditampilan di bawah panel citra Gross Primary Production. Jumlah piksel dan luas dari rentang nilai tertentu juga ditampilkan pada textbox.

\section{Kesimpulan}

Aplikasi perkiraan serapan karbon dengan metode Gross Primary Production untuk Kota Denpasar dengan input data penginderaan jauh sudah berhasil dirancang. Seluruh proses pengolahan citra dari membaca citra satelit, cropping, koreksi reflektan, penghitungan NDVI, masking, thresholding NDVI, penghitungan fAPAR, penghitungan PAR dan penghitungan Gross Primary Production sudah berhasil diimplementasi pada aplikasi. Aplikasi dapat menghasilkan informasi berupa nilai Gross Primary Production yang dituangkan dalam bentuk gambar dengan segmentasi warna, luas dari masing-masing segmen dan nilai Gross Primary Production ratarata, minimum dan maksimum. Fitur-fitur tambahan pada aplikasi seperti parsing data dari file metadata, cropping, masking dan zoom sudah mampu mendukung pengolahan citra satelit menjadi data Gross Primary Production untuk Kota Denpasar.

\section{Daftar Pustaka}

[1] "Desertification and Climate Change." [Online]. Available: http://www.unccd.int/Lists/SiteDocumentLibrary/Publications/Desertificationandclimatecha n ge.pdf.

[2] Fundamentals of Remote Sensing. Canada: A Canada Centre for Remote Sensing Remote Sensing Tutorial, 2007.

[3] S. Angel and S. Sheppard, The dynamics of global urban expansion. 2005.

[4] A. R. As-syakur, T. Osawa, and I. W. S. Adnyana, "Medium spatial resolution satellite imagery to estimate gross primary production in an urban area.," Remote Sens., 2010.

[5] J. Weier and D. Herring, "Measuring Vegetation (NDVI \&amp; EVI)," 2000. [Online]. Available: https://earthobservatory.nasa.gov/Features/MeasuringVegetation/.

[6] K. Tu, "Modeling Plant-Soil-Atmosphere Carbon Dioxide Exchange Using Optimality Principles," B.A. University of California at Santa Cruz, 2000.

[7] "NDVI $2015 . \quad$ Foundation," Anline]. http://phenology.cr.usgs.gov/ndvi_foundation.ph. [Accessed: 04-Apr-2015].

[8] "NASA," 2014. [Online]. Available: http://landsat.gsfc.nasa.gov/?page_id=7195. [Accessed: 15-Dec-2014].

[9] "Landsat8 Using Product," 2014.

[10] T. Sakamoto, A. A. Gitelson, B. D. Wardlow, S. B. Verma, and A. E. Suyker, "Estimating daily gross primary production of maize based only on MODIS WDRVI and shortwave radiation data," Remote Sens. Environ., 2011.

[11] J. B. Bradford, J. A. Hicke, and W. K. Lauenroth, "The relative importance of light-use efficiency modifications from environmental conditions and cultivation for estimation of large-scale net primary productivity," Remote Sens. Environ., 2005.

[12] "AGS99," $2015 . \quad$ [Online]. Available: http://a-a-rs.org/aars/proceeding/ACRS1999/Papers/AGS99-2.htm. [Accessed: 17-Mar-2015].

[13] S. W. Running, R. Nemani, J. M. Glassy, and P. E. Thornton, Modis Daily Photosynthesis (Psn) And Annual Net Primary Production (Npp) Product (Mod17), 3.0. 1999.

[14] Zein and M. T. A. Aziz, "Korelasi Antara Pengukuran dan Indeks Vegetasi (Studi kasus: Taman Nasional Lore-Lindu, Sulawesi Tengah)," Institut Pertanian Bogor, 2009.

[15] S. C. Black, "Estimation of Grass Photosynthesis Rates in Mixed-Grass Prairie Using Field and Remote Sensing Approaches," University of Saskatchewan Saskatoon, 2006.

[16] L. S. S, "Estimasi Emisi CO2 Dari Kebakaran Hutan," 2006.

[17] G. L. Morrison, "Solar radiation data for indonesia," Sol. Energy, 1992. 